\title{
Braiding ultrathin layer for insulation of superconducting Rutherford cables
}

DOI:

$10.1177 / 1528083716661204$

\section{Document Version}

Accepted author manuscript

Link to publication record in Manchester Research Explorer

\section{Citation for published version (APA):}

Roy, S. S., Potluri, P., Canfer, S., \& Ellwood, G. (2016). Braiding ultrathin layer for insulation of superconducting Rutherford cables. Journal of Industrial Textiles. https://doi.org/10.1177/1528083716661204

\section{Published in:}

Journal of Industrial Textiles

\section{Citing this paper}

Please note that where the full-text provided on Manchester Research Explorer is the Author Accepted Manuscript or Proof version this may differ from the final Published version. If citing, it is advised that you check and use the publisher's definitive version.

\section{General rights}

Copyright and moral rights for the publications made accessible in the Research Explorer are retained by the authors and/or other copyright owners and it is a condition of accessing publications that users recognise and abide by the legal requirements associated with these rights.

\section{Takedown policy}

If you believe that this document breaches copyright please refer to the University of Manchester's Takedown Procedures [http://man.ac.uk/04Y6Bo] or contact uml.scholarlycommunications@manchester.ac.uk providing relevant details, so we can investigate your claim.

\section{OPEN ACCESS}




\title{
Braiding Ultrathin Layer for Insulation of Superconducting Rutherford Cables
}

\author{
Sree Shankhachur Roy ${ }^{1}$, Prasad Potluri ${ }^{1 *}$, Simon $_{\text {Canfer }}{ }^{2}$, George Elwood $^{2}$ \\ ${ }^{1}$ Robotics and Textile Composites Group, Northwest Composites Centre, \\ The University of Manchester, UK. \\ ${ }^{2}$ Rutherford Appleton Lab, STFC, Oxfordshire, UK \\ * Corresponding author: prasad.potluri@manchester.ac.uk
}

\section{Key words: Superconducting magnet, Insulation, Rutherford cable, Braid, Glass fibre over- braiding, Surface Coverage, Cover factor, Organic size}

\begin{abstract}
Over braiding of superconducting Rutherford cable was used for fibre reinforcement in the composite insulation in this research. Braiding was a suitable alternative to fabric tape winding for achieving ultrathin insulation with required electrical breakdown voltage. A brief overview of the superconducting magnets, their application and requirements of insulation has been covered in order to bridge the literature gap between braiding and the superconducting magnet field of studies. Organic size coating on the fibre leaves carbon residue during high temperature treatment of the cables and hence glass fibre was desized before braiding. Braiding difficulties with desized glass fibre and possibility of braiding using compatible size coating has been discussed. The requirement of ultrathin braided layer was achieved with sufficient surface coverage with a suitable braid angle and fibre. As part of the study braid cover factor variation on the surface of the cable was investigated and it was discussed using image analysis.
\end{abstract}

\section{1) Introduction}

High performance fibre made textile substrates are widely used technical textiles for developing composite materials. The textile substrates used as reinforcement in composites are typically made using conventional textile manufacturing technologies such as weaving, braiding and winding. Composites are used mostly in the lightweight materials application such as for structural components in aerospace and automotive components ${ }^{1}$, pipes and tubes, wind turbines, bicycle frames and so on. Yet another field for composite application has been electrical insulation of cables for electromagnets operating at cryogenic temperature. Electrical insulation can be provided by the polymer or ceramic cover. However insulation for superconducting cables requires a significant amount of load bearing capability that can be achieved by fibre reinforced composites. Glass fibre tape winding is a widely used method for developing such insulation cover however further improvement for achieving thinner insulation was aimed for this research. 
In this research, braiding ${ }^{2}$ was used to apply a layer of glass fibre on flat 'Rutherford' cables for reinforcing the composite insulation. Amongst various textiles manufacturing technologies braiding is the only method that is capable of producing a helically interlaced tubular structure. The helical fibre interlacement pattern helps to produce braided sleeve at non-orthogonal orientations to tailor the structural requirements of the reinforcement in composite. Braiding has a wide range of applications in composites such as fluid transportation via pressure vessels, tubes and pipes, propeller blades, drive shaft, sports equipment etc. However for the Rutherford cable insulation, the primary aim was to produce a very thin layer of braid with sufficient surface cover and explore the associated challenges. The insulated cables will be used for developing superconducting magnets and are intended to be used for particle accelerator. This article presents different stages of over-braiding of Rutherford cable and the braid parameters. As the manufacturing involved in this study has an application in the field of superconductivity, despite the complex nature of material's superconducting phenomenon, a general introduction to superconductivity and superconducting magnet have been covered as part of the literature review.

\section{2) Overview of Superconductivity and superconducting magnet}

\section{a) Magnetism and conductivity of materials}

Earth's magnetic field $\sim 47 \times 10^{-6}$ tesla allows the compass indicators to indicate the cardinal directions. By passing electricity through conductors, the electromagnet was developed over a century ago. An electromagnet can be developed to generate far stronger magnetic fields than that of Earth's. A very important application of such magnet is Magnetic Resonance Imaging (MRI) for medical diagnosis that uses magnetic field as high as 1-3 tesla. The superconducting property of some materials (such as niobium alloys) pushed the boundary to increase the magnetic field beyond that used in MRI with the lowest economic effect compared to the alternative electromagnet systems ${ }^{3}$.

Resistivity of a material is a unique property that is inversely proportional to the conductivity. Due to an applied voltage, a constant current flow through a conductor that is opposed by a resistance within the conductor. The electrons move through solid material and interact with the crystal lattice and impurities. The continuous collisions of electrons with the atoms of the lattice produce an average velocity of electron flow resulting in constant current flow ${ }^{4}$. The electron-atom collisions decrease kinetic energy in the form of heat. In a good conductor, the interaction between electrons and the lattice is 'weak' providing low resistance. This prevents the electrons to attract each other in low temperature avoiding transition to superconducting state 5 . Hence although metals are good electrical conductor, metals with high conductivity such as silver, copper and gold do not demonstrate superconductivity ${ }^{5}$. 


\section{b) Superconducting phenomenon and zero resistance}

Superconductivity is a physical event of materials. It is primarily the disappearance of electrical resistance below a very low temperature known as critical temperature $\left(\theta_{\mathrm{c}}\right)$. Dutch physicist $\mathrm{H}$. Kamerlingh Onnes in 1911 discovered superconductivity by cooling down mercury at $4.2 \mathrm{~K}$ where Helium liquefies ${ }^{4}$. The resistance was calculated using the applied voltage across the mercury and the recorded current. The experiment showed the resistance drop from $0.11 \Omega$ to $0.00001 \Omega$ as the temperature was reduced from $4.22 \mathrm{~K}$ to $4.19 \mathrm{~K}$ and the current flow continued without noticeable loss ${ }^{4}$.

Unlike conductors, in a superconductor the electrons flow through the lattice without any collision. The superconducting state in a superconductor exists only at extremely low temperature. At near absolute zero temperature Coulomb's electron repulsion is overcome by formation of 'electron pairs' These electron pairs create a condensed state in a superconductor below an 'energy spectrum gap' separating it from the uncondensed normal electrons ${ }^{6}$. This energy gap at a superconducting state of a material decreases with increasing temperature ${ }^{5}$ hence these materials demonstrate superconducting properties only at very low temperature. Amongst all the elements, Niobium has the highest superconducting transition temperature of $9.5 \mathrm{~K}^{6}$.

\section{c) Magnetic field of superconducting magnet}

Alongside the fundamental property of extremely low resistance, superconductors show exceptional magnetic and thermal properties. If an external magnetic field is brought to an electrical conductor, magnetic field lines forms through the material due to the electric current flow. The magnetic field through the conductor is created perpendicular to the electric charge flow direction. In contrast for superconductors the magnetic field do not pass through the bulk of the material (Meissner effect) ${ }^{5}$. On the surface of the superconductor the applied magnetic field induces current. This surface current consecutively generates a magnetic field inside the superconductor equal magnitude to that of the applied field. The opposite direction of the internal magnetic field creates an absence of magnetic field inside. Instead the magnetic field exists only on the surface layer of the superconductor ${ }^{4}$. Due to the presence of current on the surface layer of the superconductor, it expels the external magnetic field. 


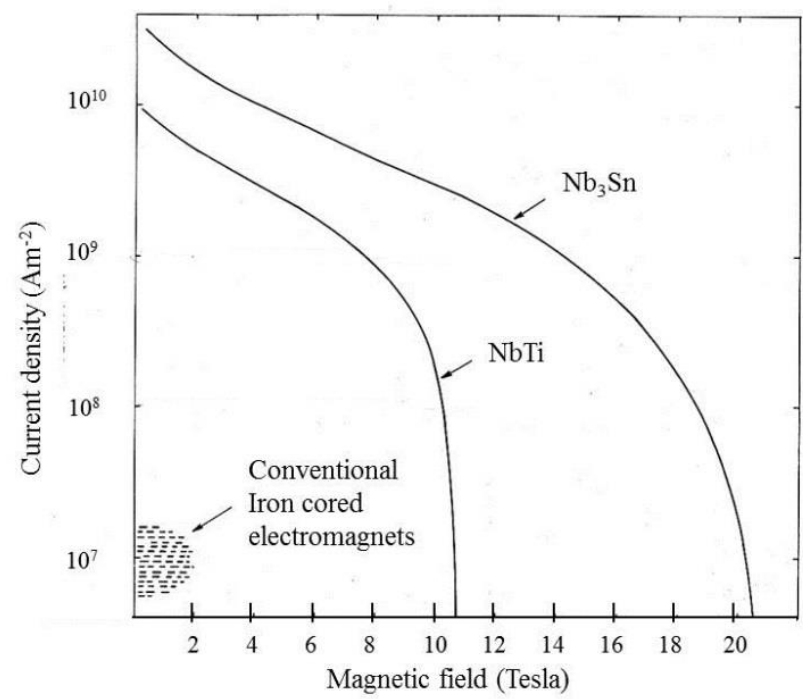

(a)

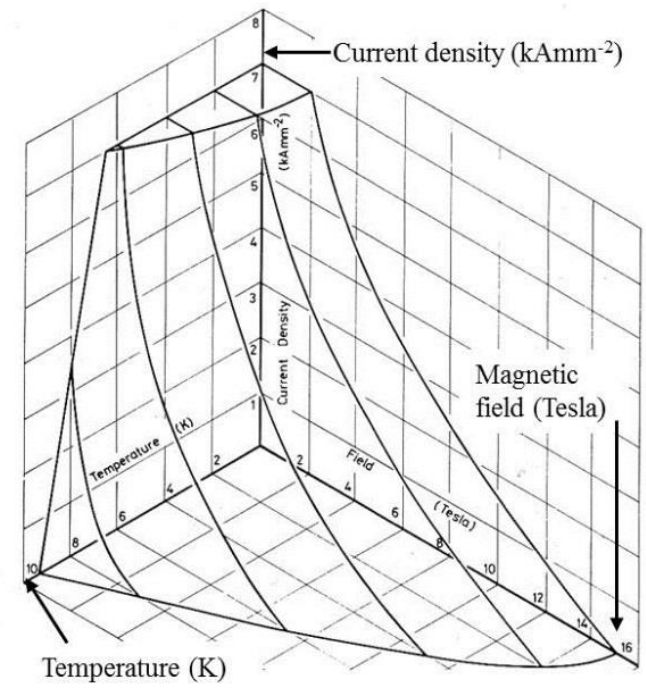

(b)

Figure 1 (a) Current density and magnetic field range of conventional iron- cored electromagnets and those of $\mathrm{NbTi}$ and $\mathrm{Nb}_{3} \mathrm{Sn}^{7}$ (b) Critical current surface of superconducting alloy $\mathrm{NbTi}^{7}$

In a superconductor the current density, magnetic field and the temperature are interrelated. When the temperature is decreased below the critical temperature the magnetic field continues to increase. However with the increasing magnetic field the current density decreases. The superconducting state prevails below a maximum applied magnetic field beyond which superconductivity does not exist. Figure 1 (b) shows the critical current surface for NbTi alloy for commercial application ${ }^{7}$.

\section{d) Types of superconducting magnets}

Early discoveries of superconductors are type-I in which superconductivity 'quenches' or disappears until the exposure of an external magnetic field that is usually the critical magnetic field. The transition to zero resistance occurs over a small temperature range. On the other hand, in type-II, two critical fields $\mathrm{H}_{\mathrm{c} 1}$ (low) and $\mathrm{H}_{\mathrm{c} 2}$ (high) exist ${ }^{3}$. Beyond $\mathrm{H}_{\mathrm{c} 1}$, in type-II superconductors only strong magnetic field penetrates inside however it preserves superconductivity simultaneously ${ }^{8}$ as it forces out 'weak' magnetic field creating non-superconducting regions. This property of superconductivity at high magnetic field made the type-II suitable for magnet applications however it requires sustaining higher critical current ${ }^{3}$. Introduction of structural defect fulfils the requirement of higher critical current that can be achieved and controlled by heat treatment and other metallurgical processes ${ }^{3}$. Type-II superconductors are mainly alloys and pure metal such as niobium $(\mathrm{Nb})$ that has the highest critical field (0.206 tesla $)^{4}$. The critical magnetic field is the lowest field strength that removes the superconductivity by increasing the energy that destroys the electron pairs mentioned earlier in Type-I superconductors 5 . 


\section{e) Applications of superconductivity and superconducting magnets}

For decades people have relied on high magnetic fields for various applications from medical diagnosis to the study of physics. The application fields of superconducting magnetic properties are wide and growing. In order to produce high field magnets superconductors are economical compared to conventional electromagnets ${ }^{6}$. As mentioned in the previous section, one of the most important applications of high field superconducting magnet is medical diagnosis using (MRI). High magnetic field allows higher resolution imagery. Unlike X-ray, MRI is not harmful and it can detect various soft tissues. This allows the 3D reconstruction of the image of the interior of the body using computer tomography ${ }^{6}$. Magnetically levitating transport system (MAGLEV) using superconducting magnet are under research to overcome the technical challenges ${ }^{6}$. However superconducting magnet are extensively used for providing magnetic fields in the equipment such as particle accelerators for the research of physics. The insulation for the superconducting Rutherford cable in this research is aimed at the application in dipole bending magnets for particle accelerators.

Apart from the superconducting magnets, in order to reduce energy waste, superconducting cables have been developed for power cables. By utilising the zero resistance property of the high temperature superconducting material, the longest $(\sim 1 \mathrm{~km})$ superconducting power cable in operation connects two transformer stations in Essen, Germany ${ }^{9}$. The key advantage of using superconducting cable is the power density; fitting high current cables in small spaces such as city centres.

\section{3) Superconducting magnets for particle accelerator}

One of the most popular superconducting materials is niobium-titanium (NbTi) alloy. Both NbTi and $\mathrm{Nb}_{3} \mathrm{Sn}$ alloys are type-II superconductors and operate below $20 \mathrm{~K}$. These alloys provide high current density with critical magnetic field up to 20 tesla $^{10}$. In the study of particle physics, to investigate the fundamental nature of matter a synchrotron particle accelerator (Figure 2a) is used. Magnetic fields within these accelerators are used to focus and bend ${ }^{7}$ the beams of high energy charged particles. The approximately circular orbit of the particles is achieved using bending magnets with a dipole field ${ }^{11}$ to bend the particle beams. These high energy particle beams are collided together at extremely high speed to study the pieces produced. Powerful and large superconducting radio frequency accelerating cavities are used to achieve the required high energies for particle collision. The particle accelerator chambers are operated in cryogenic temperatures ${ }^{6}$. Superconducting magnets achieve high and stable magnetic fields which are not feasible with conventional copper conductor electromagnets. 


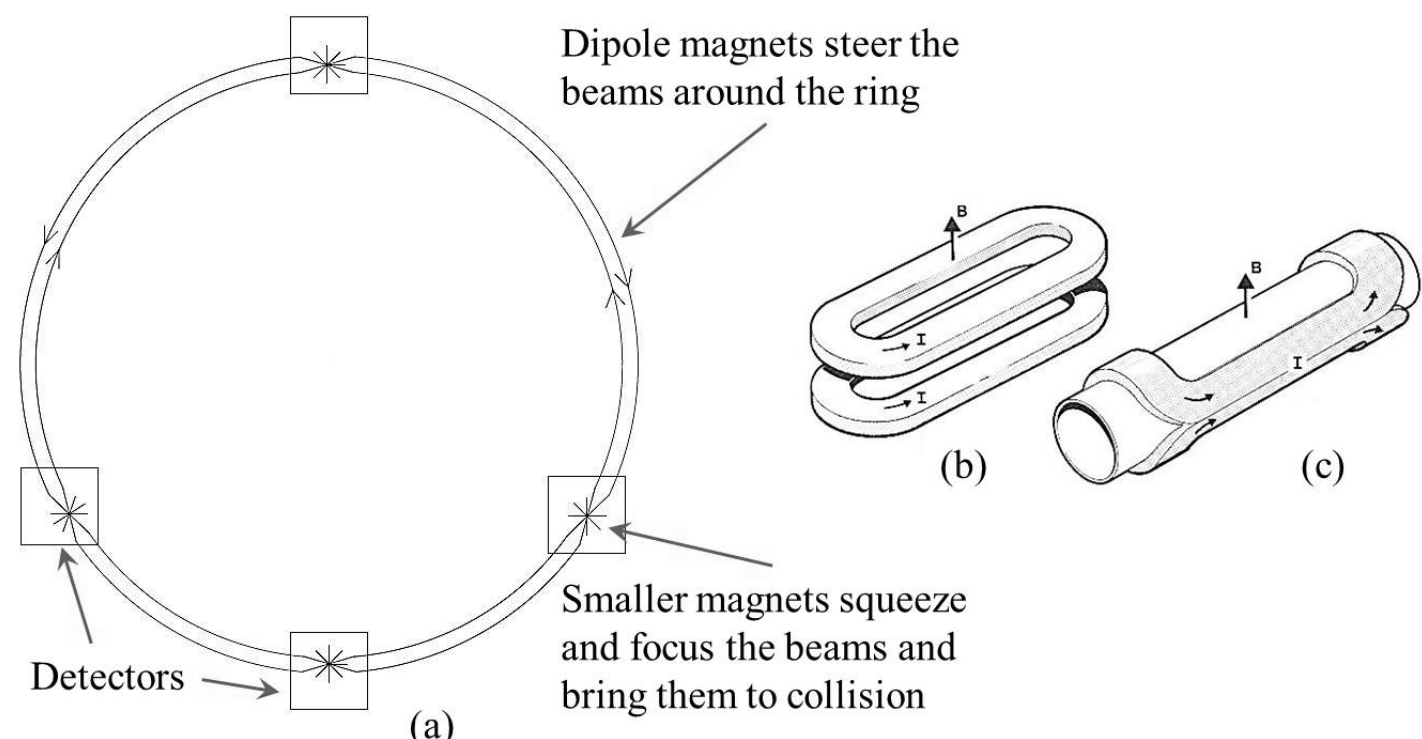

Figure 2 Left: (a) Schematic of the ring structure of Large Hadron Collider (LHC), a particle accelerator used for research in particle and high energy physics. It consists of a $27 \mathrm{~km}$ circumference of superconducting magnets placed in the tunnel used to direct the high energy particle beam; Right: Superconducting cable winding configurations for transverse field $\operatorname{magnet}^{7}$ (b) Race track coils (c) Curved saddle coils

The magnetic field is used transverse to the particle beam in an accelerator to bend the beam into a circular trajectory (Figure 2a). The field is required to be either dipole or quadrupole. Quadrupole magnets are used to focus the beam, as the particles tend to repel each other. MRI magnets use a solenoid coil winding configuration but to achieve the required transverse field direction for particle accelerator, a racetrack configuration is required (Figure 2b). Solenoids are circular cylindrical winding of superconducting wires. Practical winding configuration for traverse field dipole magnets may be designed in 'saddle' shape (Figure 2c) in order to align the magnetic field lines perpendicular to the length of the magnet with extremely high field homogeneity.

Superconducting dipole magnets used for accelerators provide high magnetic fields up to 15 tesla ${ }^{12-14}$. These magnets use superconducting materials such as $\mathrm{NbTi}$ and $\mathrm{Nb}_{3} \mathrm{Sn}$ filaments in a copper matrix strand of up to $1 \mathrm{~mm}$ diameter. These strands are then transposed to make a cable in the rope or braid structure. However in order to reduce self-field losses in dipole magnets the strands are formed into a flat Rutherford cable ${ }^{7}$ (Figure 4a). Although niobium-tin $\left(\mathrm{Nb}_{3} \mathrm{Sn}\right)$ operates in higher critical magnetic field and temperature, it is weaker and more brittle than $\mathrm{NbTi}^{7}$. The ductility of NbTi facilitated easier and cheaper fabrication ${ }^{3}$. The individual filaments of NbTi in each strand are as thin as $6 \times 10^{-3} \mathrm{~mm}^{15}$ and each strand contains up to $6300 \mathrm{NbTi}$ filaments. In order to achieve thermal stability of the high field magnet material, the superconducting strands are combined with a copper matrix. The role of the copper is to act as a stabiliser in the event of a quench, both thermally to conduct heat and electrically 
to conduct the high current. It prevents the superconductor meltdown due to local temperature rise as a result of increasing current ${ }^{3}$.

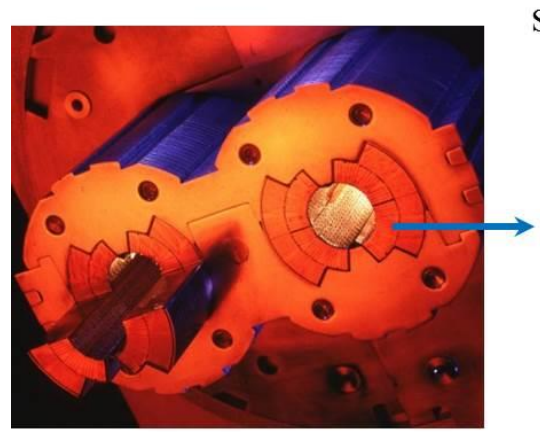

(a)

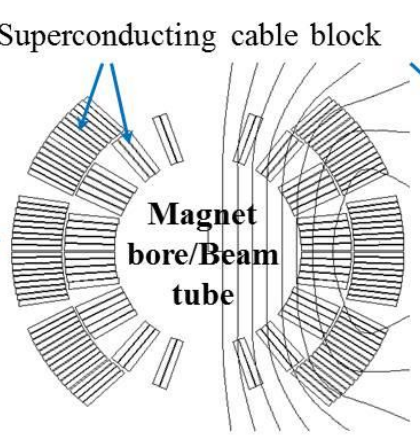

(b)

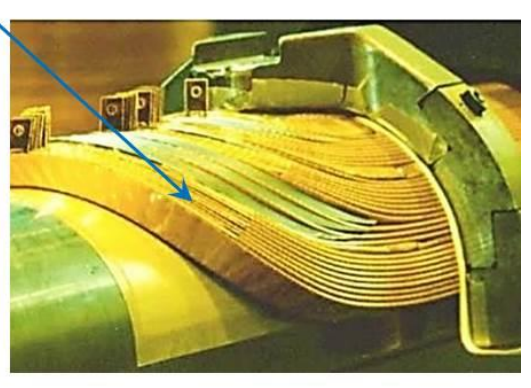

(c)

Figure 3 (a) Superconducting coil in the LHC dipole (b) Schematic of winding blocks in a dipole magnet ${ }^{16}$ (c) Rutherford superconducting cable blocks for a saddle type dipole winding (on a winding mandrel) ${ }^{17}$

The cables are turned multiple times to form a coil block (Figure 3b) placed in the desired shape (Figure 2c). The insulation is required between the turns hence it is called 'turn-to-turn'. Another form of insulation requirement is turn to ground. In the following sections the cable insulation process discussed has been focused on turn-to-turn insulation only.

\section{4) Braiding of Rutherford cables}

\section{a) Insulation requirements}

One of the widely used methods of insulating the cables is use of epoxy resin. However for high magnetic field superconducting magnets, the epoxy is preferred to be reinforced with high performance fibres. The high field conductors apply compressive forces in the range of mega Newton per meter length of magnet. Glass fibre fabric tape wrapping was a conventional method of reinforcement for such insulation. However tape wrapping results in edge overlap that provides a thickness build-up that is not always suitable for achieving very thin layer insulation. Braiding was first recommended ${ }^{14}$ as a potential cable insulation for reducing thickness as the process apply a single layer on the cable. Two dimensional circular maypole ${ }^{18}$ braiding is a unique way of producing a tubular substrate. Though the braid cross section is circular, nevertheless the braided sleeve takes the cross-sectional shape of the core. This flexibility of reshaping the cross-section enables over-braiding of the Rutherford cable that has a relatively rectangular cross section making it a suitable alternative for fibre tape.

The requirements of the fibre component of the insulation include the need to have good radiation resistance, temperature resistance of around $700^{\circ} \mathrm{C}$, reasonable cost, commercial availability and free 
of boron. S glass (R glass in Europe) has a higher recrystallization temperature $\left(\sim 750^{\circ} \mathrm{C}\right)$ than that of E glass ${ }^{13}$. Although E-glass is easily available commercial glass fibre, one of the constituents of the fibre is boron trioxide $\left(\mathrm{B}_{2} \mathrm{O}_{3}\right)^{19}$. It acts as a fluxing agent and hence it reduces melting temperature of glass and also its presence can influence fibre-matrix de-bonding in composite ${ }^{20}$. Unlike E-glass, Sglass have no or a little boron component making it a suitable fibre for braided insulation ${ }^{21}$.

Thickness of the insulation layer is an important parameter for magnet design. In order to develop insulation for a high field $(15 \mathrm{~T})$ superconducting dipole magnet a set of key specifications was established ${ }^{14}$ focusing the issues and limitations. In the review, authors prioritised the integrity of the insulation over electrical breakdown strength. For a standard fibreglass laminate (G10) the required breakdown voltage is $20-30 \mathrm{kV} / \mathrm{mm}$. However the $15 \mathrm{~T}$ dipole magnet stores high energy density hence the insulation integrity is also very important.

Engineering current density, $\mathrm{J}_{\text {Eng }}=\frac{\text { Current, } \mathrm{I}}{\text { Total cross sectional area of cable and insulation, A }}$

In equation 1 , engineering current density is inversely proportional to the total cross sectional area hence a thin layer of insulation improves the current density as presented by Blackburn et al. ${ }^{22}$. However the insulation needs to be able to withstand handling whilst winding the magnet. Hence thin layer risk insulation robustness that is required for the application. A $10 \%$ higher current density from a thinner insulation was indicated ${ }^{14}$ to be less important than insulation robustness that enables high integrity manufacturing. Hence an optimum thickness of 0.15-2 $\mathrm{mm}$ on each side of the cable or 0.3$0.4 \mathrm{~mm}$ turn to turn was a target to achieve by using braiding process.

\section{b) Braiding preparation and Rutherford cable specification}

In this study two different variations of cable were used for the insulation investigation. The two types of cables are made of 18 and 40 strands and are designed for different types of magnet applications. The strand number variation subsequently changes the dimension of the cable (Table 1). Both the cables bend along the direction of its length and width. For braiding a core, ideally it is required to keep the core at the centre of the braid ring without any lateral or vertical movement. To avoid the swinging in upward direction which was displacing the cable from the centre, the cable reel was placed in a position in which the cable swings downwards. The end of the cable was passed through a guide inline to that of the braiding point after the cable was withdrawn gradually from the cable reel. As the cable was braided it was passed over a flanged bearing roller guide to prevent the lateral displacement of the braiding point. The along the length bend of the cable had a low radius of curvature. Hence it was possible to accommodate the curvature between the braid fell point and the let 
off position from the reel of the cable without placing the reel too far behind the braiding machine. The cable was passed through two small diameter rings before it appeared to the point of braiding. The cable was traverse wound onto the reel hence as the delivery position shifted after unwinding each turn, the reel position was changed manually. A negative let off of the reel was used that provided high tension on the core. This set up provided the required stability of the cable with linear take up that prevented inconsistency of braid parameters within a sample.

Table 1 Cable specification

\begin{tabular}{|c|c|c|c|}
\hline Cable notation & Number of strands & Width, $\mathrm{W}_{\mathrm{c}}(\mathrm{mm})$ & Thickness, $\mathrm{t}_{\mathrm{c}}(\mathrm{mm})$ \\
\hline $\mathrm{N}$ & 18 & 10 & 1.9 \\
\hline $\mathrm{W}$ & 40 & 21.46 & 1.85 \\
\hline
\end{tabular}

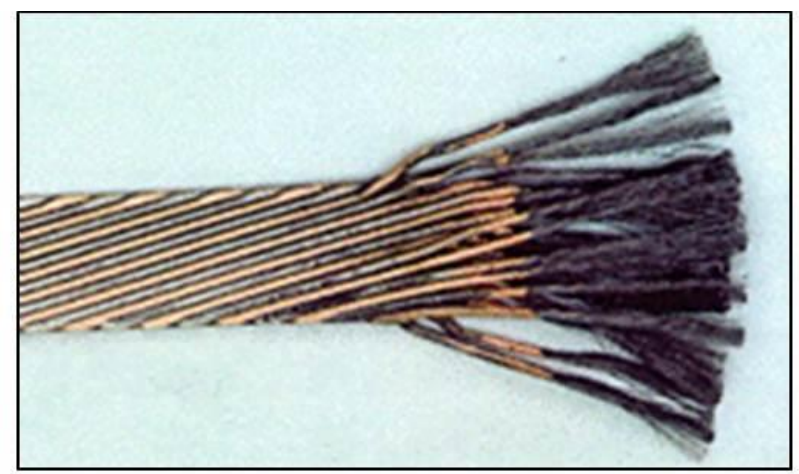

(a)
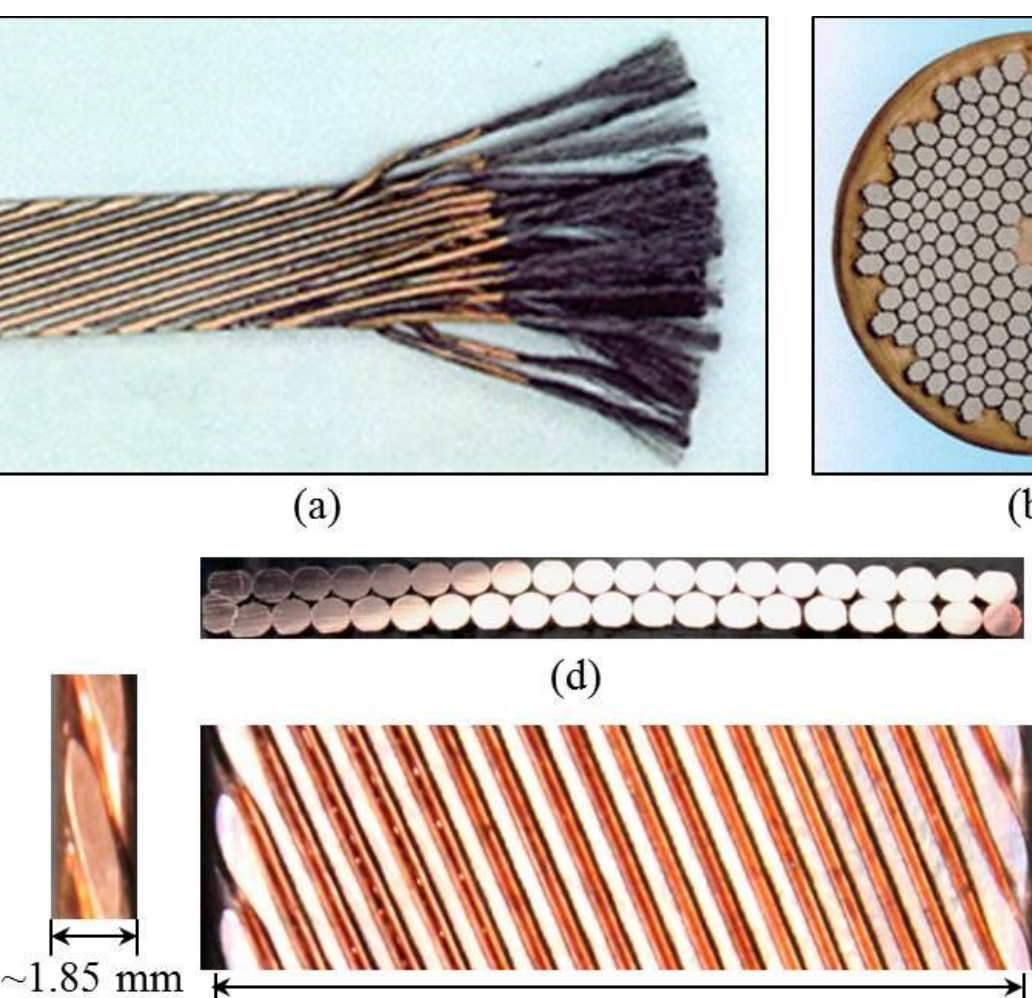

(e) (d)
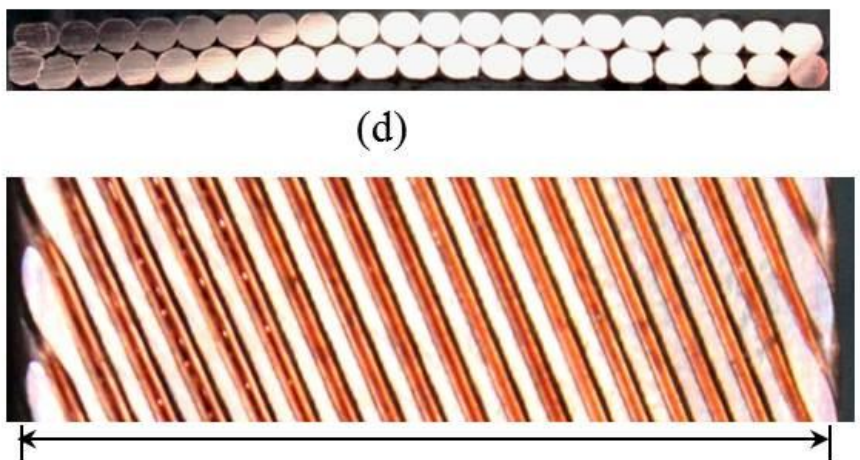

(f)

Figure 4 (a) Rutherford cable with 36 strands used in $\mathrm{LHC}^{15}$ (b) A single strand cross section view that contains $6300 \mathrm{NbTi}_{\text {filaments }}{ }^{15}$ (c) NbTi filaments $\left(0.006 \mathrm{~mm}\right.$ thick) in copper matrix ${ }^{15}$ (d) Images of 40 strand copper cable used for braiding-cross section view (e) Side view of the cable (f) Top view of the cable $\left(\mathrm{W}_{\mathrm{c}}\right)$ 
The cable was cut using a wire cutter and as it is a bundle of multiple strands (also known as wires) it usually left the cut section deformed with sharp edges. A section of the cable was set in resin before cutting and polishing to take the cross section view of the cable to prevent any deformation. Although the cable appears to be flat and rectangular, the image of the cross-section (Figure $4 \mathrm{~d}$ ) of the cable shows the width wise bend of the cable. However as the braided cables are placed in a stack and pressure was applied during resin infusion, the applied pressure would minimize the width wise bend.

\section{c) Organic size alternative for glass fibre coating}

The superconducting cables are required to perform at high and very low temperature. Hence improved strength retention properties of the insulation at varying temperature became essential to avoid breakdown due to thermal expansion or contraction. S-glass fibre reinforced composite became a choice to achieve the required mechanical properties. However the commercially available glass fibres are coated with organic sizing materials to withstand abrasion and evade fibre damage. Fibre tow damage appears in the form of filamentation during the manufacturing process. Sizing application lubricates the filaments to reduce friction between the tows and machine parts and also improve the anti-static properties.

The glass fibre roving with organic sizing material is unsuitable for the insulation application. The cables are heat treated at high temperature $\left(650^{\circ}-700^{\circ} \mathrm{C}\right)^{14,23}$ for about 7 days ${ }^{14}$. The heat treatment is carried out in vacuum or in presence of an inert $\operatorname{gas}^{24}$ (argon) to avoid oxidation of the cable surface ${ }^{23}$. Due to absence of oxygen, the organic sizing on the glass fibre roving leave carbon residue (Figure $5 b)$ that decrease the dielectric strength of the superconducting cable. Hence it is necessary to remove the organic size before the resin impregnation.

In order to use size-free fibre for insulation, two previous studies ${ }^{14,21}$ followed two different manufacturing approach. One of these studies ${ }^{21}$ de-sized the material and re-sized it before use and another study ${ }^{14}$ eliminated the use of organic size on the fabric tape with inorganic type. In the first study $^{21}$ commercially applied conventional size was removed from a S-glass woven tape $(0.1 \mathrm{~mm}$ thick) developed by JPS. Re-sizing was carried out to provide minimum level of robustness for winding purpose. A small amount of high temperature size was applied to the tape that degraded during heat treatment to provide a light grey appearance. The laminated insulation provided sufficient electrical breakdown strength of $15 \mathrm{kV} / \mathrm{mm}^{21}$.

In the other manufacturing approach ${ }^{14}$ the organic size was replaced by an inorganic (ceramic) precursor with the aim of eliminating the resin impregnation step. Although heat treatment for superconductor provided robust ceramic insulation it was a porous structure that allows penetration of the liquid helium ${ }^{14}$. This is desirable from a thermal stability point of view. A glass fibre tape impregnated in the ceramic precursor was wrapped around the cable for insulation ${ }^{14}$. In contrast helium porosity is not feasible for epoxy impregnated insulation. 
If the fibre de-sizing before cable insulation is the preferred manufacturing route, several other studies $^{12,13,23,25}$ suggested a fatty acid (palmitic) as a re-sizing material. The high boiling point of palmitic acid $\left(\sim 350^{\circ} \mathrm{C}\right)$ made it a suitable material to be used for high temperature treatment of the superconducting cables. However traces of carbon remained in glass fibre insulation layer ${ }^{13}$ after the high temperature heat treatment had been carried out in an inert (argon) environment. Although little traces was considered to be not detrimental to the insulation the other study ${ }^{25}$. Inorganic size chromium oxide was also used in the study ${ }^{13}$ however as a side effect the size led to the corrosion of the metal parts of the weaving machine. Another alternative to organic size was found to be polyimide $(\mathrm{PI})^{24}$ that was relatively thermally stable polymer because of its highly aromatic chemical structure. The study ${ }^{24}$ presented that PI re-sized S-glass insulation provided improved tensile and shear properties along with electrical breakdown voltage.

\section{d) De-sizing and re-sizing of glass fibre and braiding}

The two major methods of removal of size from the glass fibre are dissolving the size and graphitization in air. Because of the unavailability of the sizing composition dissolving the size was not a suitable method. In contrast high temperature burning out of size ensures removal of organic binders. A cheese of fibre was heat cleaned inside a large furnace at $350{ }^{\circ} \mathrm{C}$ to burn off the added size. There was a visible colour change indicating size burn off from the fibre.

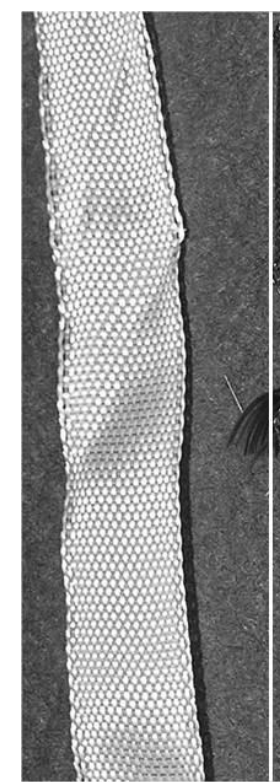

(a)

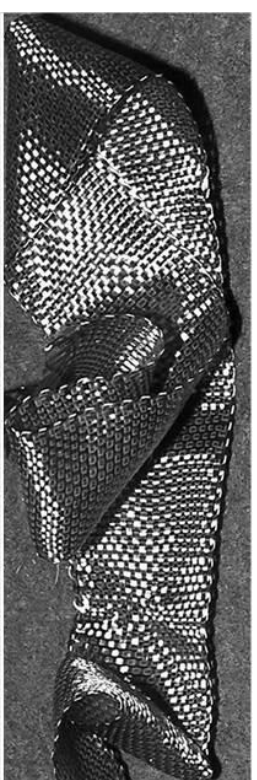

(b)

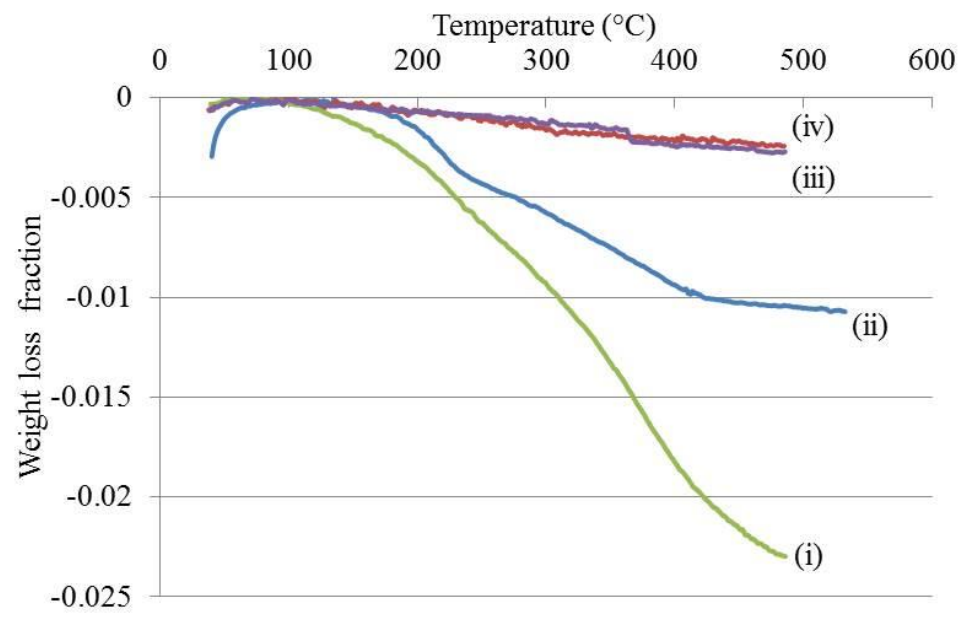

(c) AR argon (ii)

—Desized Argon (iv) —Desized Air (iii)

(c)

Figure 5 Organic size coated glass fibre woven tape (a) before heat treatment (as received) (b) Carbon residue from burnt organic components on the glass fibre tape after heat treatment at $660^{\circ} \mathrm{C}$ in vacuum (c) Graph representing TGA analysis of HYBON 2001 E glass fibre as received (AR) and after desizing in air and inert atmosphere 
A Thermo-Gravimetric Analysis (TGA) of the fibre was carried out at RAL. The TGA essentially comprises of a very precise balance with the sample hanging in a furnace, it is used to measure changes in mass with respect to temperature. Figure 6 shows the results from the TGA of the E glass. The 'As Received' (AR) E glass has a sizing, when this is heated in air the sizing can combust and be fully removed. When the as received E glass is heat treated in argon as the atmosphere is inert the organic sizing cannot be burnt off and fully removed, it degrades to carbon and the weight decreases by $1 \%$. Later the desized E glass was put in the TGA and there was very little weight loss either in air or in argon. This indicates that the heat cleaning removed the most size from the fibre. It was suggested that a weight change at a temperature higher than $350^{\circ} \mathrm{C}$ would indicate that the heat cleaning temperature was too low for maximum possible weight loss. However as it appears in Figure $5 \mathrm{c}$, at $350^{\circ} \mathrm{C}$ the as received glass fibre had a weight loss of $\sim 1.40 \%$ in air environment. The fibre datasheet ${ }^{26}$ suggests that the fibre has a Silane size content of $0.55 \pm 0.15 \%$. This indicates that quoted amount of size was completely removed from the fibre.

Desizing of the glass fibre roving decreased the tow abrasion resistance thus reducing the processability of the tow. Without resizing, braiding was attempted using the desized fibre and filament breakage was observed during braiding and bobbin winding. Filament entangling was also increased that is also known as filamentation (Figure 6a) creating a 'fibrous web'. During bobbin winding the breakage was reduced by reducing both applied tension and winding speed. Reduced number of broken ends on the bobbins reduced the filament entangling during braiding. After multiple attempts, a small length of cable was over-braided successfully using very low bobbin rotational speed and carrier tension. Sufficient cable surface coverage was achieved by reducing the take-up speed. However convergence length was reduced due to low take-up and rotational speed that eventually increased the inter-tow friction causing filamentation between the braid ring and the braid fell point. Subsequently gradual reduction in cross sectional area of the fibre roving led to breakage of the tow. An electronic atomizer (Figure 6d) was used to spray a stream of fine water particles to the fibres in the convergence zone. Fine water particles tend to provide some adhesion between filaments within the tow as well as lubricate the tows to carry out weaving of glass fabric. Typical sizing include antistatic agent that was also removed during desizing. Hence water particles allowed dissipation of static electricity along the fibre surface as glass fibre is non-conductive. With the aid of water particle spray, two small length samples were produced but braid angle consistency was not possible to maintain as the roving breakage after each short length of braiding continued. Similar observation was found by a previous study ${ }^{21}$ in which desized glass fibre tape was found to be susceptible to damage during automated winding. 

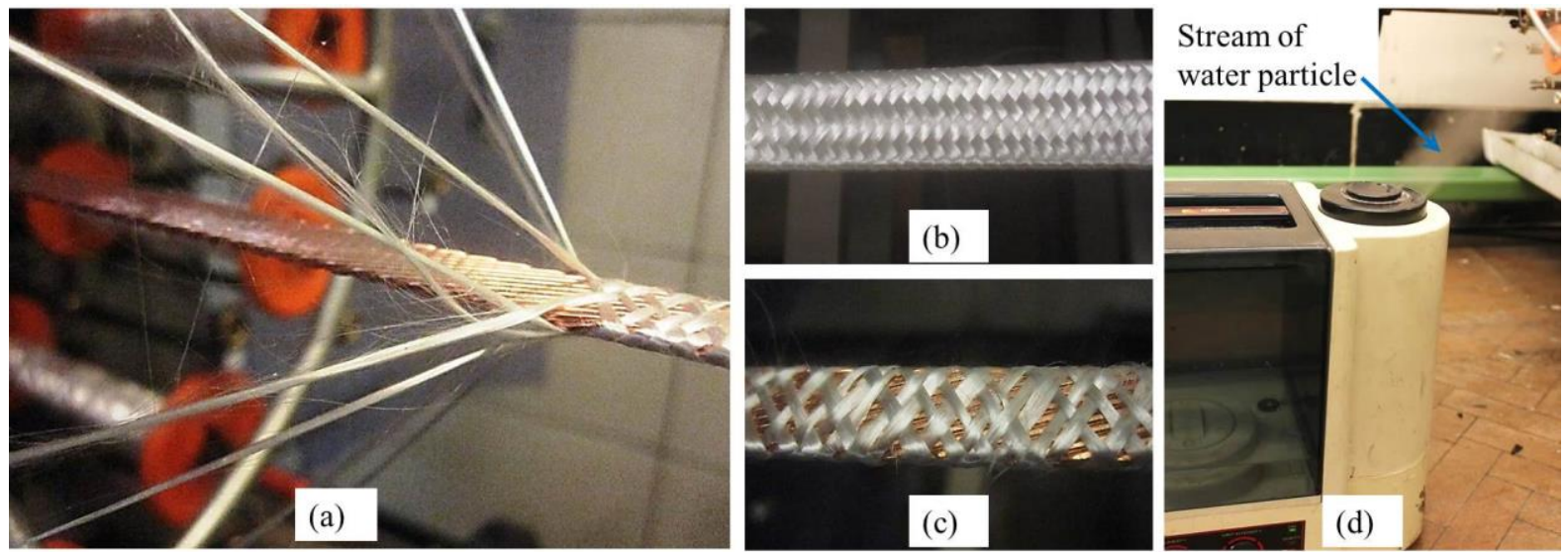

Figure 6 Braiding Rutherford cable using desized glass fibre (a) Filamentation and fibre breakage during braiding (b) Cable braided with the aid of water particle lubrication (c) Insufficient coverage due to the reduced speed of the braiding process to avoid fibre breakage $(\mathrm{d})$ Atomizer spraying fine water particles

To make the heat cleaned glass roving functional for braiding, different coating were applied. Water soluble poly vinyl alcohol (PVA) and epoxy were coated onto the roving and these coatings provided adequate binding of the fibres in the roving which would require a washing off the size with water after the braiding. However even though silane works as a water repellent coupling agent, water adsorption may degrade composite mechanical properties by affecting the interface of the resin and fibre $^{27}$. Hence PVA and epoxy coating was later avoided.

Ethylene glycol $\left(\mathrm{HO}-\mathrm{CH}_{2}-\mathrm{CH}_{2}-\mathrm{OH}\right)$, widely used as an antifreeze, is used as an anti-static agent for textile sizing. It was also used for re-sizing the de-sized glass fibre roving. It has a boiling point of $195^{\circ} \mathrm{C}$ so it can be removed during the heat treatment. However roving breakage appeared to be a setback during the coating process as the roving had to pass several guides and dryer drum. Reducing the number of guides the process was replicated and the coating was completed successfully with minimum filament breakage. Ethylene glycol coated glass fibre was used for braiding and the roving breakage was reduced significantly. However to avoid the total process of removal and addition of sizing the manufacturing route was replaced by choosing a glass fibre with compatible size.

\section{e) S-2 glass fibre braiding for insulation}

Since there were difficulties in re-sizing the E-glass fibre roving, a compatible size coated glass yarn was acquired for the braiding purpose. The linear density of this yarn is 66 tex that allowed braiding at higher angle with optimum surface coverage as well as required low thickness. The glass fibre yarn had a sizing (933 size, AGY, Huntingdon, USA) that is stable at $350^{\circ} \mathrm{C}$ and above and compatible with epoxy resin system $^{28}$.

The braiding requirement for the insulation layer had a very low thickness and sufficient surface coverage. Potluri et al. ${ }^{29}$ analysed biaxial braid geometry and presented relationships between the 
braid angle, yarn width and thickness. As yarn width is proportional to the factor $(\sin 2 \alpha / \sin \alpha)$, with an increasing braid angle the yarn width will decrease. In addition, with the corresponding decrease in yarn width, braid thickness will increase ${ }^{29}$. The roving width of 300 tex E glass fibre was higher compared to that of 66 tex S-2 glass fibre. Hence a regular (2/2 interlacement) braid pattern was produced using an equipment with 24 carrier capacity. High angle braiding with E glass roving produced layer thickness of $0.25 \mathrm{~mm}$ and above (Table 2) on each side of the cable. As the braid thickness was a required insulation parameter, lower braid angle (below $\pm 45^{\circ}$ ) reduced the layer thickness however this compromised the surface coverage.

As the S2 glass fibre had a lower yarn width and linear density, in order to achieve sufficient surface coverage a 48 carrier braiding machine (Figure 7) was used for over-braiding the cables with a biaxial regular braid. Although the surface coverage was observed to be varying across the width (discussed in the section $5 b)$ the required braid thickness on each side of the cable $(0.2 \mathrm{~mm})$ was achieved. Several samples were produced with different braid angles for comparative study.

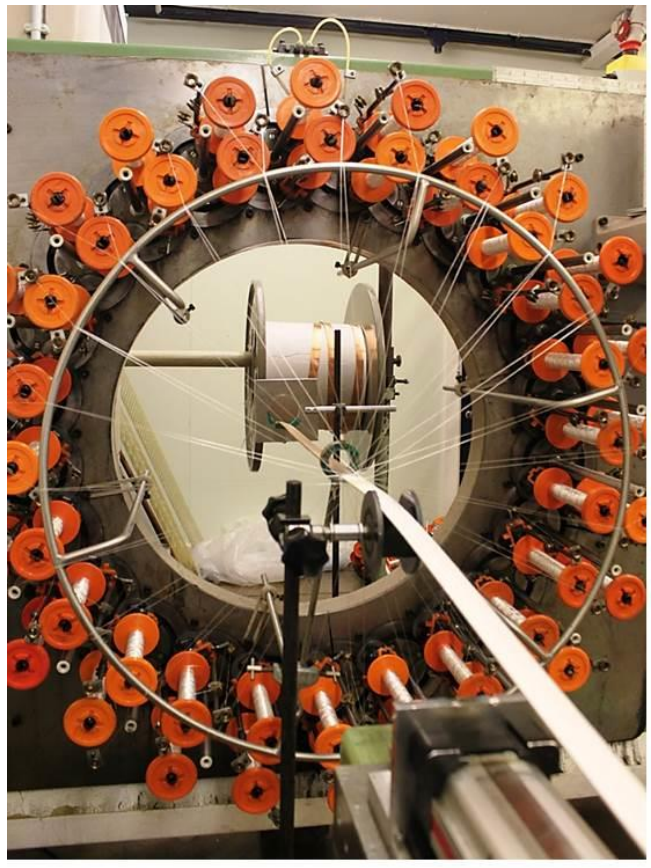

(a)

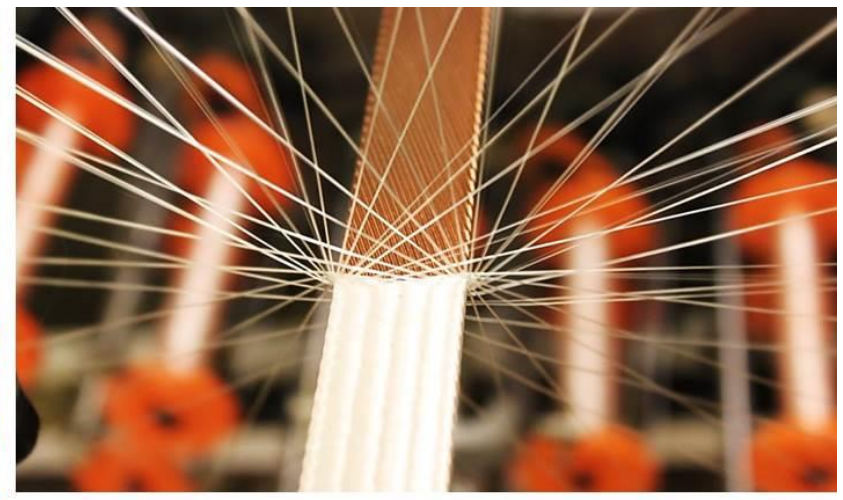

(b)

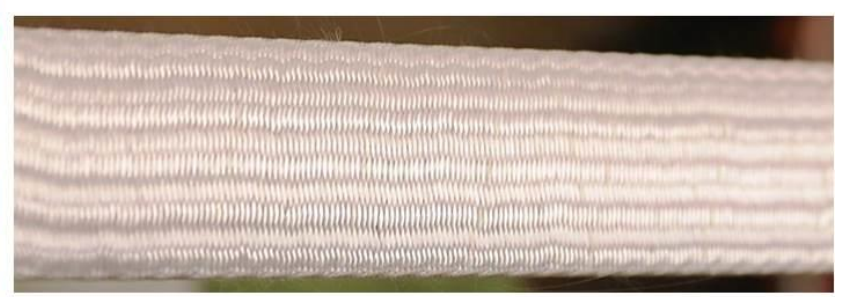

(c)

Figure 7 Braiding using S-2 glass with compatible size that provided optimum thickness with no major fibre damage

Later over-braided cable sections of each braid angle were put in a stack and resin impregnated. After curing the cable stack was heat treated. Followed by the heat treatment the cable stack was tested for electrical breakdown following BS 7831:1995. The electrical breakdown of the braided composite 
insulation was at over $6 \mathrm{kV}$ with the braid surface coverage as low as $~ 96.4 \%$ (sample W51 in Table 3). This satisfied the minimum requirement for the insulation. Therefore the rest of the manufacturing was carried out using this fibre. The braid angle was varied to change the braid thickness and cover in order to achieve maximum required electrical breakdown of $10 \mathrm{kV}$.

\section{5) Analysis of braid parameters}

\section{a) Braid thickness and surface coverage}

The thickness of the braided layer on the cable was measured using a micrometre. By using both flat/flat jaws of a micrometre, over-braided cable thickness was measured. The braid insulation thickness $\left(t_{b}\right)$ was calculated using the equation 2 where $t_{c}$ is the Rutherford cable thickness and $t_{i}$ is the over-braided cable thickness on the wider side of the cable.

$$
t_{b}=\frac{\left(t_{i}-t_{c}\right)}{2}
$$

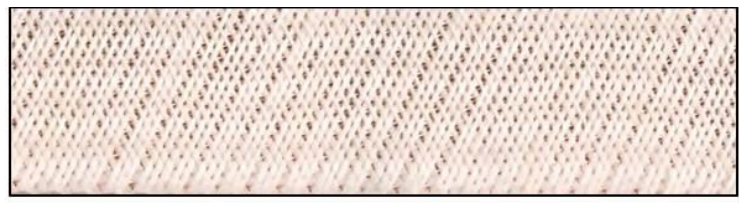

(a)

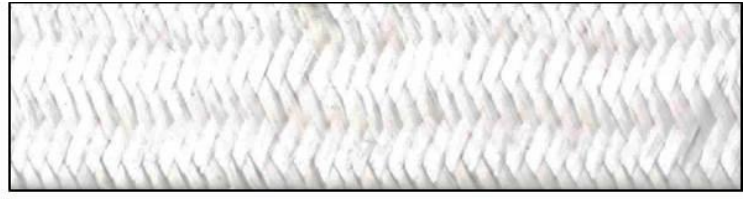

(b)

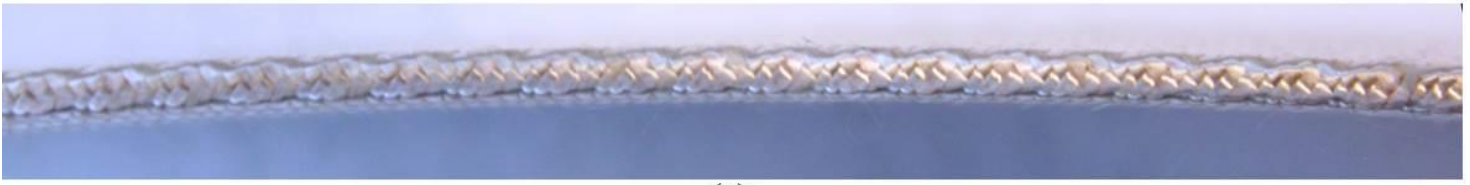

(c)

Figure 8 Braid cover variation on the cable (a) Partially uncovered regions on the cable (top view) (b) Cable surface mostly covered by braid (top view) (c) Fully covered surface of the cable (side view)

As the braid angles were changed in different samples, the surface coverage of the cable specimens was different (Figure 8). Cover factor (CF) indicates the extent of surface coverage by a fabric or braid when placed onto a tool. For a circular cross section core, $\mathrm{CF}$ of a biaxial braid structure can be calculated using the following formula ${ }^{30}$ where $\mathrm{W}_{\mathrm{y}}$ is the yarn width, $\mathrm{N}_{\mathrm{c}}$ is the total number of carriers, $\mathrm{R}$ is the effective radius of the over-braided core and $\alpha$ is the braid angle.

$$
C F=1-\left(1-\left(\frac{\mathrm{W}_{\mathrm{y}} \mathrm{N}_{\mathrm{c}}}{4 \pi \mathrm{R} \cos \alpha}\right)\right)^{2}
$$

Since when the cable cross section resembles a rectangular cross section (Figure 4), equation 3 was modified to equation 4 to calculate the cover factor. In the equation 4 , ' $t$ ' and ' $W$ ' are the effective thickness and the effective width of the over-braided cable respectively. 


$$
\mathrm{CF}_{\text {rec }}=1-\left(1-\left(\frac{\mathrm{W}_{\mathrm{y}} \mathrm{N}_{\mathrm{c}}}{4(\mathrm{~W}+\mathrm{t}) \cos \alpha}\right)\right)^{2}
$$

Effective thickness (t) and width (W) of the cable with the over braided insulation layer can be expressed using the equation 5 where $t_{c}$ is the cable thickness and $t_{b}$ is the insulation layer thickness on one side of the cable.

$$
\mathrm{t}=\mathrm{t}_{\mathrm{c}}+\mathrm{t}_{\mathrm{b}}
$$

$$
\mathrm{W}=\mathrm{W}_{\mathrm{c}}+\mathrm{t}_{\mathrm{b}}
$$

The CF prediction using equation 3 and 4 considers that the braid parameters such as the yarn width, spacing, braid angle are uniform around the circumference. However as the cable cross section has unequal length of sides, the narrower sides had $100 \%$ surface coverage unlike the wider sides. In order to get an approximate coverage from actual braid sample, the surface coverage was measured by means of image analysis. A Java based program aimed for image processing called ImageJ, developed by the National Institutes of Health (USA), was used for the study surface coverage on the wider side of the cable.

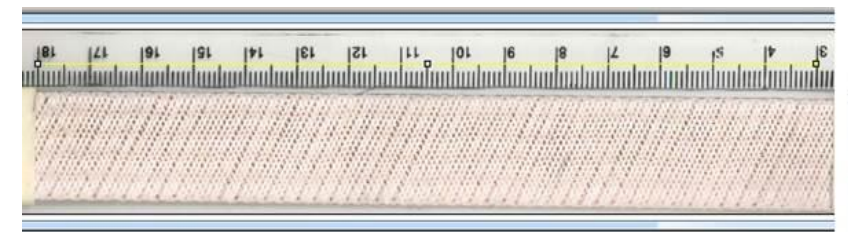

(a)

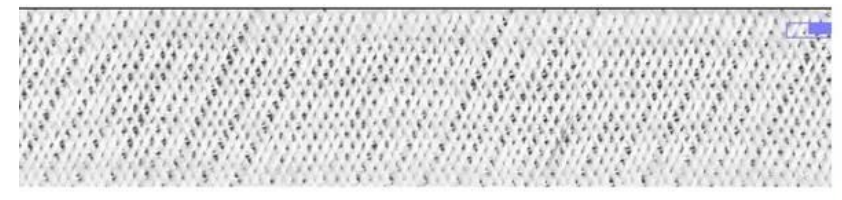

(b)

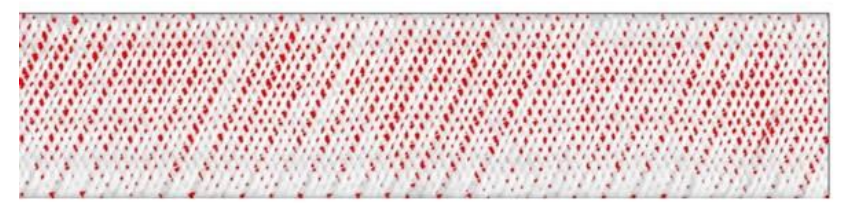

(c)

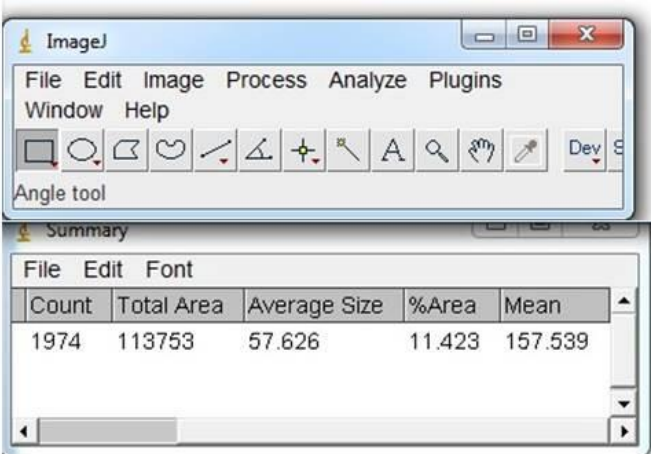

(d)

Figure 9 (a) Scanned image of the over-braided cable with a ruler placed next to it for dimension calibration (b)

Grayscale image of the cropped area for coverage analysis (c) Separating the visible fibres from the uncovered surface area by applying threshold on the grayscale image (d) Software windows indicating the tools and the results of the analysis 
The braided cable samples were scanned with a ruler next to these (Figure 9a) by using a flatbed scanner to acquire the images those were used for analysis. By using the length from the ruler the image dimension was calibrated. After the calibration the image was cropped to separate 'region of interest' that required analysis. The cropped image was then sharpened to detect the outline of uncovered areas and the image was changed to grayscale. Once the threshold option is activated, by default the fibre covered areas of the braid layer was separated. As the uncovered areas were small, in order to focus on the uncovered area for analysis, the covered area was changed to a light background (Figure 9c). At this stage the image thresholds selects the areas uncovered however it also includes parts of the cable edge with full surface coverage as uncovered. A possible reason for such segmentation is the image quality. The scanned image is a two dimensional representation of a three dimensional surface of the braid. During the image processing the shades on the image was observed to be sections segmented as uncovered surface. The threshold option shows a histogram that distributes the pixel intensities in the image. By moving the 'slider bar', regions those were selected as uncovered and highlighted in red colour can be changed. The histogram was changed to deselect the edge area of the cable for individual braids based on the fully covered surface appearance. By using the software tool the uncovered segmented area percentage was measured. This method was an approximate representation of the surface coverage from the actual braid parameters.

The braid parameters were measured from wider side only to calculate the cover by using equation 4 so the data presented in the Table 2 and Table 3 were comparable to the image analysis of wider side only.

Table 2 Thickness and Coverage data for the cable insulation using 300 tex E-glass fibre

\begin{tabular}{|c|c|c|c|c|c|}
\hline $\begin{array}{c}300 \text { tex E- } \\
\text { glass sample } \\
\#\end{array}$ & $\begin{array}{c}\text { No. of } \\
\text { roving per } \\
\text { braid }\end{array}$ & $\begin{array}{c}\text { Braid thickness } \\
\text { on wider side, } \\
\mathrm{t}_{\mathrm{b}}(\mathrm{mm}) \pm \mathrm{SD}\end{array}$ & $\begin{array}{c}\text { Braid } \\
\text { angle }\left(^{\circ}\right) \\
\pm \mathrm{SD}\end{array}$ & $\begin{array}{c}\text { Cover }(\%) \text { from } \\
\text { equation } \\
{[\mathrm{CF} \times 100]}\end{array}$ & $\begin{array}{c}\text { Average cover (\%) of } \\
\text { cable circumference } \\
\text { from Image analysis }\end{array}$ \\
\hline $\mathrm{W} 45$ & 24 & $0.173 \pm 0.01$ & $38.7 \pm 0.6$ & 96.5 & 98.5 \\
\hline $\mathrm{W} 44$ & 24 & $0.235 \pm 0.01$ & $52.5 \pm 1.0$ & 97.3 & 99.9 \\
\hline $\mathrm{W} 43$ & 24 & $0.245 \pm 0.01$ & $55.0 \pm 0.3$ & 98.1 & 100 \\
\hline $\mathrm{W} 42$ & 24 & $0.275 \pm 0.01$ & $63.8 \pm 0.4$ & 99.8 & 99.7 \\
\hline
\end{tabular}


Table 3 Thickness and Coverage data for the cable insulation using 66 tex S-2 glass fibre

\begin{tabular}{|c|c|c|c|c|c|}
\hline $\begin{array}{c}\text { 66 tex S-2 } \\
\text { glass sample } \\
\#\end{array}$ & $\begin{array}{c}\text { No. of } \\
\text { yarns per } \\
\text { braid } \\
\text { W56 }\end{array}$ & $\begin{array}{c}\text { Braid thickness } \\
\text { on wider side, } \\
\mathrm{t}_{\mathrm{b}}(\mathrm{mm}) \pm \mathrm{SD}\end{array}$ & $\begin{array}{c}\text { Braid } \\
\text { angle }\left(^{\circ}\right) \\
\pm \mathrm{SD}\end{array}$ & $\begin{array}{c}\text { Cover }(\%) \text { from } \\
\text { equation } \\
\text { [CF } \times 100]\end{array}$ & $\begin{array}{c}\text { Average cover (\%) of } \\
\text { cable circumference } \\
\text { from Image analysis }\end{array}$ \\
\hline W55 & 48 & $0.142 \pm 0.01$ & $63.2 \pm 0.8$ & 84.8 & 88.6 \\
\hline W51 & 48 & $0.154 \pm 0.00$ & $68.4 \pm 0.6$ & 96.4 & 97.6 \\
\hline W54 & 48 & $0.173 \pm 0.01$ & $70.09 \pm 0.8$ & 96.3 & 98.3 \\
\hline W53 & 48 & $0.198 \pm 0.01$ & $74.8 \pm 0.8$ & 99.5 & 99.1 \\
\hline W52 & 48 & $0.223 \pm 0.01$ & 81.8 & 98.6 & 100 \\
\hline
\end{tabular}

\section{b) Variation in surface coverage across the cable width}

The comparative surface coverage from prediction and image analysis is presented in Figure 10. The difference in measuring surface coverage is higher for lower angle due to the braid parameter variation around the structure. For this study as the cables were flat a scanned image of the braid was in one plane that aided the image analysis. The maximum difference of surface coverage between the prediction and the image analysis was $7.8 \%$. This indicates that the error\% is likely to be higher from prediction method because of considering the average values of individual parameters.

As appears in the bar chart, the CF calculated using the modified equation had higher deviation from image analysis. Although average values of the parameters were used for calculation, a close observation on the over-braided cables showed variation in surface coverage within the wider side of the cable. It is apparent from the close observation that the surface coverage was higher on both edges of the wider side of the cable than that at the middle. 


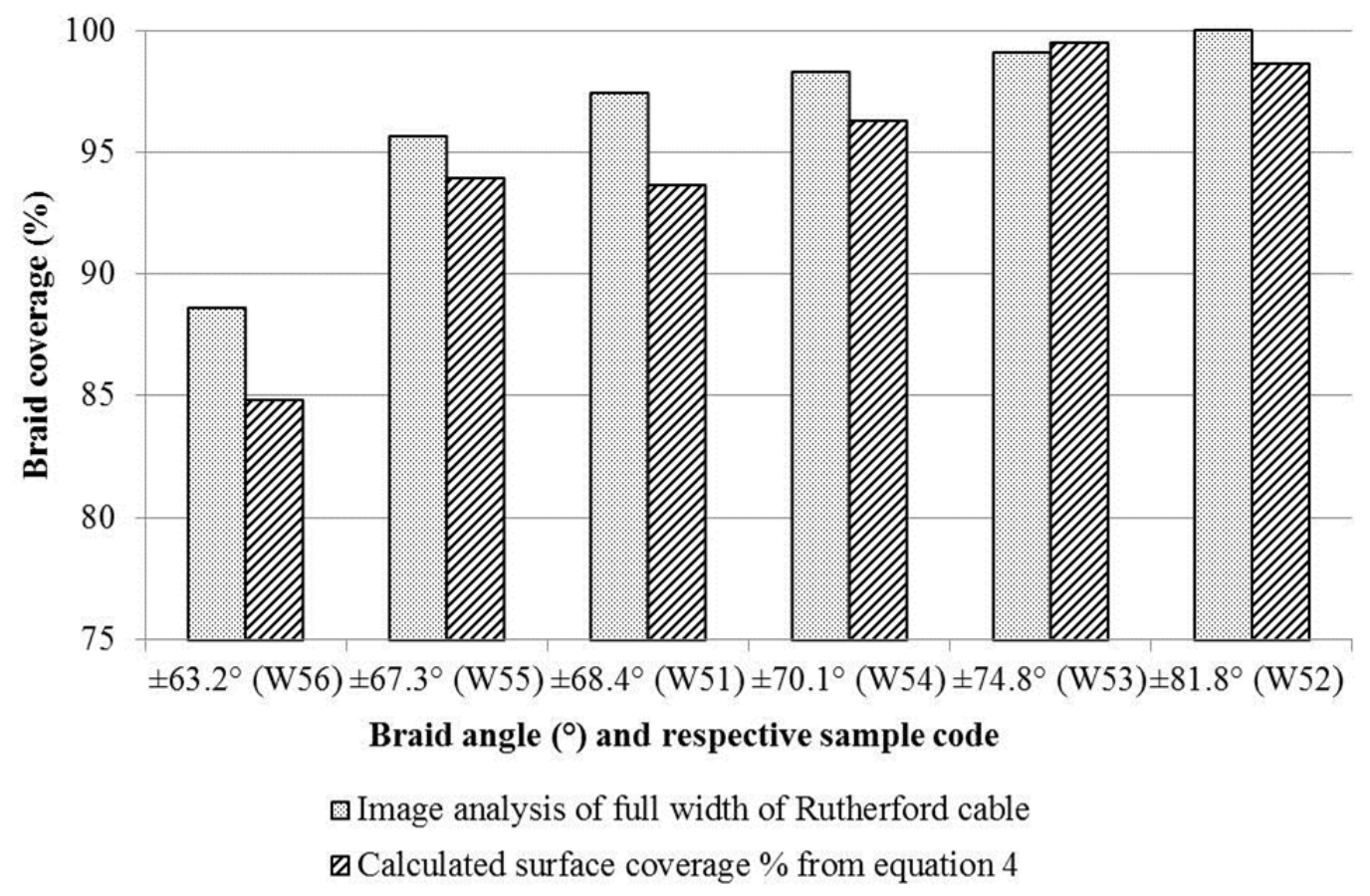

Figure 10 Comparative surface coverage of 66tex braid on the cable predicted using equation and measured using image analysis tool ImageJ

The equation 4 can predict $\mathrm{CF}$ closer to the actual for a braided structure with uniform yarn width and braid angle around the circumference. Hence the predicted coverage value had error compared to that from the image analysis. Based on the apparent cover variation, the braid on the cable was clustered (Figure 11a) in three sections- the two edges and the intermediate. Figure 11a presents the $22 \mathrm{~mm}$ wide over-braided Rutherford cable and full surface coverage was observed on both edges. About $15 \mathrm{~mm}$ wide section at the centre of the cable had $\sim 94.5 \%$ surface coverage illustrating the apparent variation in cover.

By using the ImageJ software the intermediate section was cropped and the cover\% was analysed. As the braid angle was increased the width of the intermediate section with less than $100 \%$ surface coverage decreased simultaneously increasing the fully covered width on both edges. By taking these section width measurements the surface cover variation is presented in Figure 11b. 


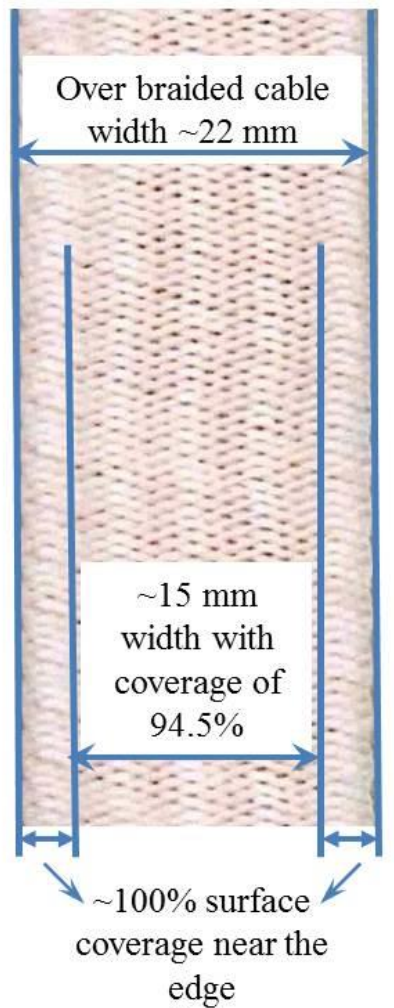

(a)

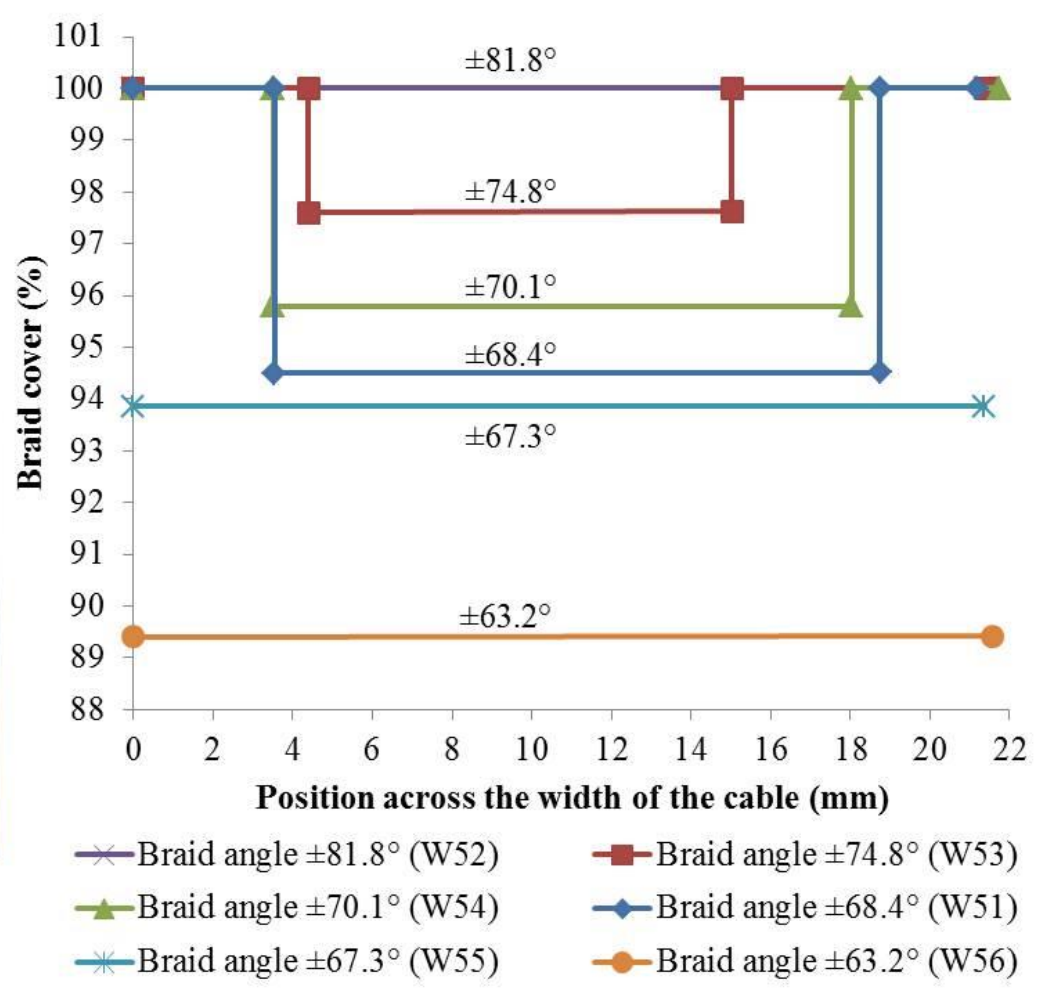

(b)

Figure 11 (a) Braid coverage variation across the cable width for $\sim 68.4^{\circ}$ braid angle (sample W51) with 94.5\% coverage across $15 \mathrm{~mm}$ width at the cable centre and $\sim 100 \%$ coverage over $\sim 3.5 \mathrm{~mm}$ width at both edge (b)

Braid cover variation due to different braid angle across the width of the cable

\section{6) Discussion and conclusion}

Initial braiding attempt was successful however in order to meet the insulation requirements the glass fibre was desized. Following the difficulties to braid the desized glass fibres, successful resizing and braiding was carried out. However the fibre was later changed to suit the requirements. The fibre change led to the change in braiding using 48 carriers. Several braiding angle was produced for over braiding the cable. Because the cable had a resembling rectangular cross section the braid structure around the mandrel had difference in parameters. This had an effect on the surface coverage on the wider side of the cable. The surface cover variation within the cable wider side was observed between the braid angle $\pm 65^{\circ}$ and $\pm 75^{\circ}$. With braid angles outside that range the cover was more uniform across the width. As the cover factor depends on the braid parameters, this range will vary with a different type of tow or yarn. Finally upon completion of composite manufacturing, the electrical breakdown requirement was successfully met. Braid structures with less than $100 \%$ surface coverage achieved thinner insulation and despite the coverage variation around the width the required breakdown voltage was achieved. 


\section{Acknowledgement}

The authors thank the Rutherford Appleton Laboratory operated by Science Technology Facilities Council (STFC) for providing the materials for this research. In addition the authors also wish to thank Mr Roy Gidley for arranging the glass fibre desizing at Fothergill Engineered Fabrics Ltd and Dr Vivek Koncherry for providing help in re-sizing the material.

\section{References}

1. Branscomb D, Beale D and Broughton R. New directions in braiding. J Eng Fibers Fabr. 2013; 8: 1124.

2. Potluri P. Braiding. In: Nicolais L, Borzacchiello A and Lee SM, (eds.). International Encyclopedia of Composites. New York: Wiley, June 2012.

3. $\quad$ Fishlock D. A guide to superconductivity. Macdonald, 1969.

4. Owens FJ and Poole CP. The New Superconductors. Springer, 1996.

5. Kresin VZ and Wolf SA. Fundamentals of Superconductivity. Springer US, 1990.

6. Ford PJ and Saunders GA. The Rise of the Superconductors. Taylor \& Francis, 2004.

7. Wilson MN. Superconducting Magnets. Clarendon Press, 1986.

8. Ginzburg VL and Andryushin EA. Superconductivity. World Scientific, 2004.

9. Scheuerle S. Operation of Longest Superconducting Cable Worldwide Started (AmpaCity project), KIT-Press Releases. April 2014.

10. Meuris C and Rifflet J-M. Superconducting magnets for the LHC. Clefs CEA $n^{\circ} 56$ (The French Alternative Energies and Atomic Energy Commission). 2008, p. 4-9.

11. Livingston MS and Blewett JP. Particle accelerators. McGraw-Hill, 1962.

12. McIntyre P, Blackburn R, Diaczenko N, et al. 12 Tesla hybrid block-coil dipole for future hadron colliders. Applied Superconductivity, IEEE Transactions on. 2001; 11: 2264-7.

13. Devred A, Bredy P, Durante M, Gourdin C, Rey JM and Reytier M. Insulation Systems for NB3SN Accelerator Magnet Coils Fabricated by the "Wind and React" Technique. In: Balachandran UB, Hartwig KT, Gubser D and Bardos V, (eds.). Advances in Cryogenic Engineering Materials. Springer US, 2000, p. 143-50.

14. Baynham D and Canfer S. NB3SN Accelerator Magnets-Insulation Review. WAMS-2004 Workshop on Accelerator Magnet Superconductors. 2004, p. 63.

15. CERN_The_European_Organization_for_Nuclear_Research. LHC Machine Outreach- Super conducting cable (available at: http://lhc-machine-outreach.web.cern.ch/lhc-machineoutreach/components/cable.htm). 2016.

16. Bottura L. Introduction to Accelerator Physics Superconducting Magnets. CERN accelerator school 2012.

17. Gupta R. Magnet design and coil optimization, USPAS Course on Superconducting Accelerator Magnets, Superconducting Magnet Division, Brookhaven National Laboratory. 2003.

18. Kyosev Y. Braiding Technology for Textiles. Elsevier Science, 2014.

19. Hearle JWS. High-performance fibres. Woodhead Publishing Ltd in association with The Textile Institute, 2001.

20. Canfer S, Baynham E and Ellwood G. Insulation Development - Conventional Insulation. Final Report v.6, CARE-NED Work Package 4, CCLRC Rutherford Appleton Laboratory, 2007. 
21. Canfer S, Ellwood G, Baynham DE, Rondeaux F and Baudouy B. Insulation development for the next European dipole. Applied Superconductivity, IEEE Transactions on. 2008; 18: 1387-90.

22. Blackburn R, Fecko D, Jaisle A, McInturff A, McIntyre P and Story T. Improved S-2 Glass Fabric Insulation for Rutherford Cable. Applied Superconductivity, IEEE Transactions on. 2008; 18: 1391-3.

23. Arkan T, Chichili D and Terechkine I. Studies of S-2 fiberglass insulation for Nb3Sn cable. TD-98063, FNAL, 1998.

24. Canfer S, Baynham DE and Greenhalgh R. Insulation development for the next European dipole. AIP CONFERENCE PROCEEDINGS. IOP INSTITUTE OF PHYSICS PUBLISHING LTD, 2006, p. 298.

25. Devred A. - Insulation systems for Nb3Sn accelerator magnet coils manufactured by the wind \& react technique. IEEE TRANSACTIONS ON APPLIED SUPERCONDUCTIVITY 2002; - 12: - 1237.

26. HYBON®2001 roving Technical Datasheet, PPG Fiber Glass (http://www.ppg.com/glass/fiberglass/products/documents/2001_rev42008_.pdf). 2014.

27. Nishioka GM. Adsorption/desorption of water on glass fiber surfaces. Journal of Non-Crystalline Solids. 1990; 120: 34-9.

28. AGY. 933 S-2 Glass® Yarn. AGY.

29. Potluri P, Manan A, Francke M and Day RJ. Flexural and torsional behaviour of biaxial and triaxial braided composite structures. Composite Structures. 2006; 75: 377-86.

30. Potluri P, Rawal A, Rivaldi M and Porat I. Geometrical modelling and control of a triaxial braiding machine for producing 3D preforms. Composites Part A: Applied Science and Manufacturing. 2003; - 34: - 492. 